\title{
Are European fiscal rules that bad? Discretionary fiscal policies in New Member States
}

\author{
Bettina Fincke and Marcin Wolski
}




\title{
Are European fiscal rules that bad? Discretionary fiscal policies in New Member States
}

\author{
Bettina Fincke ${ }^{\dagger 1}$ and Marcin Wolski ${ }^{\dagger 2,3}$ \\ ${ }^{1}$ Bielefeld University, Department of Business Administration and \\ Economics \\ ${ }^{2}$ Bielefeld University, Bielefeld Graduate School of Economics and \\ Management (BiGSEM) \\ ${ }^{3}$ University of Amsterdam, Center for Nonlinear Dynamics in \\ Economics and Finance (CeNDEF)
}

\begin{abstract}
There is no clear-cut evidence on how the adoption of the European fiscal standards influences discretionary fiscal policies within the Member States. This study investigates that phenomenon on the example of the 2004 enlargement. The results show that the effects of the adoption of EU fiscal rules bring a statistically significant change towards more countercyclical behavior. The results are robust for different model specifications, including alternative time spans and correcting for the possible influence of the financial crises and political forces. Interestingly, the year 2004 did not have any significant impact on the change in fiscal policies in the Old Member States, suggesting that the EU entry might motivate new members to run more prudent budgetary policies.
\end{abstract}

Keywords: discretionary fiscal policy, New Member States JEL Classification Numbers: E62, O52

\footnotetext{
${ }^{\dagger}$ The corresponding e-mails are bfincke@wiwi.uni-bielefeld.de and mwolski@wiwi.unibielefeld.de. Marcin Wolski acknowledges the financial support from the European Doctorate in Economics - Erasmus Mundus (EDEEM).
} 


\section{Introduction}

Fiscal arrangements belong to the most criticized aspects of the European Union's (EU) internal policy (Candelon et al., 2010). A widely cited reason for that concerns the inability of the EU governments to run stabilizing fiscal policies having the Maastricht Treaty (MT) and the Stability and Growth Pact (SGP) in the background (Wyplosz, 2006; Gali and Perotti, 2003; Candelon et al., 2010). However, there has been no clear-cut evidence on how the EU fiscal rules affect discretionary fiscal policies nor what effects they pose on business cycles within the EU. Some studies prove a significant change in fiscal behavior after the adoption of the MT or the SGP fiscal rules, whereas other research shows the opposite.

This paper contributes to the topic by assessing the influence of the adoption of the EU fiscal standards on discretionary fiscal behavior empirically, on the example of the $2004 \mathrm{EU}$ enlargement. Moreover, in order to determine whether the EU entry was a core event which influenced fiscal policies among the New Member States, the analysis compares the tendencies in the fiscal behavior between them and the Old Member states.

The study is carried out on all the New Member States (NMS) that joined the EU in 2004; Cyprus, Czech Republic, Estonia, Hungary, Latvia, Lithuania, Malta, Poland, Slovakia and Slovenia. Following the literature, different model specifications are applied to correct for possible biases. The first one, is the simplest one and similar to the approach taken by Gali and Perotti (2003). It estimates the influence of the output gap on discretionary fiscal decisions using the fixed effects panel technique and assuming the existence of a structural break in 2004. To correct for the possible bias resulting from the financial crisis and the sovereign debt crisis in the Euro zone, we carry out the robustness check by adding a proxy variable, reflecting the situation in the loan market, and by cutting the time span of the analysis in 2008. The fifth model combines the last two specifications. The time span of the study has been limited by data availability and quality and, therefore, covers years 2000-2012.

To further investigate this phenomenon, the study focuses on the comparison of discretionary fiscal policies between the NMS and Old Member States (OMS). The OMS comprise 15 Member States which were in the EU before 2004 (Gali and Perotti, 2003), i.e. Austria, Belgium, Denmark, Finland, France, Germany, Greece, Ireland, Italy, Luxembourg, the Netherlands, Portugal, Spain, Sweden and the United Kingdom.

Interestingly, a remarkable and significant switch towards counter-cyclical fiscal behavior is observed for the NMS, especially in the most recent years, with no similar effect on the OMS. Among all the models for the latter, the only well-specified one suggests that the OMS were running acyclical fiscal policies for the entire period, driven mostly by external factors rather than complying with the EU fiscal rules.

The remainder of this paper is organized as follows. Section 2 brings forward the recent results on the topic and discusses the influence of fiscal policies on a business cycle. Section 3 investigates the changes in discretionary fiscal policies 
before and after the $2004 \mathrm{EU}$ enlargement. Additionally, we carry out the robustness check to assess the validity of the results. Section 4 summarizes and discusses some concerns regarding the results.

\section{Literature review and motivation}

Thinking of fiscal policy and its influence on the business cycle, one should distinguish between the effects of automatic stabilizers and discretionary actions. The former relates to the natural budget responses to the business cycle fluctuations (Candelon et al., 2010). For example, the revenues from taxes should increase during upswings so that the budget balance becomes larger. Likewise, when there is a recession, the budget balance should decrease as a consequence of, for instance, increased unemployment spending. In short, automatic stabilizers work as a natural mechanism to accumulate capital during booms and spend it during downswings. This all makes the business cycle less vulnerable and aims to provide solid economic growth (Wyplosz, 2006).

However, fiscal authorities are able to stipulate the economy beyond the automatic stabilizers' level. Such actions are called discretionary fiscal policy. Following Kydland and Prescott (1977), it may be driven by the time inconsistency of economic decisions or could be a straightforward consequence of political motivation (Pendleton, 1938; Alesina et al., 2008). An example of a discretionary action could be a change in the tax levels or a revision in government investment policy, for example.

A common view supposes that once a budget is balanced, discretionary actions should be avoided and the reaction to business cycle fluctuations should be left for automatic stabilizers only (European Comission, 2001; Beetsma, 2001; Artis and Buti, 2000). Looking at the EU countries, the condition of a balanced budgetary position has not been always satisfied, mostly because when the European Monetary Union (EMU) was introduced, fiscal policy became the only macroeconomic management instrument. Therefore, it is unlikely that Member States would resign from it easily, violating the balanced budget plan (Wyplosz, 2006).

Excessive discretionary policy could have dramatic consequences for the economy (Wyplosz, 2006). It can not only drive the amount of public debt beyond the sustainable level but can also exacerbate the business cycle or/and foster uncertainty in the markets. The current situation in Europe, with many economies facing fiscal difficulties, reveals these problems. For about five years now EU and especially Euro zone members have been impaired by the financial and debt crisis. Enormous financial rescue programs had to be arranged in order to support seriously debt-troubled economies, such as Greece for instance, and to restore financial stabilization. This assistance is tied to requirements to implement strict austerity measures (European Commission, 2013). By now the Euro zone members Ireland, Greece, Spain and Portugal receive financial support. Recently, also Cyprus applied for assistance.

In order to induce sound fiscal performance and to limit the excessive dis- 
cretionary actions within the EU, the MT implemented basic fiscal rules. They refer to the upper deficit and debt ceilings which each country has to respect, i.e. 3 percent deficit-to-GDP and 60 percent debt-to-GDP ratio. Since their introduction in 1992, they have been steadily modified in order to make them more accurate. In 1997 they were extended by the SGP and in 2005 by the decision of European Council entitled 'Improving the Operation of the Stability and Growth Pact'. ${ }^{1}$ As a result, the performance of the EU fiscal rules has been improved, however, they still have some drawbacks (Buti et al., 2003; Wyplosz, 2006).

The biggest critique of the EU fiscal arrangements comes from the fact that they might limit the flexibility of national fiscal authorities too much, especially during recessions (Gali and Perotti, 2003), but also during recently observed financial crises. Consequently, governments would not be able to follow countercyclical policies and impose balanced budgetary plans because they would be absorbed by fighting external shocks instead or they would be facing internal political pressure.

Scholars have tried to explain empirically whether those threats are justified. The results are, however, ambiguous. Two basic concepts arise from the literature. The first one, proved by Buti et al. (1997); Gali and Perotti (2003) and Wyplosz (2006), states that discretionary fiscal policies in the EMU countries were pro-cyclical before 1992 and acyclical afterwards. ${ }^{2}$ The second concept refers to studies of Von Hagen (2005) and Candelon et al. (2010) who also confirm that before 1992 the discretionary fiscal policies in the EMU were pro-cyclical, however, they remained pro-cyclical after the MT was signed. An interesting conclusion from Candelon et al. (2010) is that the empirical results are very susceptible to the time spans of the analysis. In fact, using similar methodology to Gali and Perotti (2003) but expanding the data set by two years only, Candelon et al. (2010) obtained the opposite results.

This study contributes to the discussion by expanding the scope of the analysis to the NMS and includes the most recent years. Additionally, our dataset consists of quarterly data having more degrees of freedom and making the analysis more robust.

\section{The 2004 enlargement}

Fiscal policies in the NMS have been characterized by a strong heterogeneity among countries with some running pro-cyclical and others running countercyclical policies (Schneider and Zapal, 2005). However, none of the studies treated the characteristics of fiscal policies in accordance with a structural break in 2004 - a year when the NMS officially became a part of the EU and adopted its fiscal standards. Moreover, previous research took a very narrow view on the recent situation of fiscal policies in the NMS. In fact, none of the studies

\footnotetext{
${ }^{1}$ For a detailed analysis of the evolution of fiscal rules in the EU, see Wyplosz (2006).

${ }^{2}$ The term 'acyclical' refers to Gali and Perotti (2003) and means that there was no significant impact of discretionary policy on the business cycle fluctuations.
} 
analyzes the NMS in isolation after 2006. Eventually, we may find an evidence in favor of the pro-cyclicality of fiscal policies in the NMS until 2006 with barely any insight on what happened afterwards.

To assess whether the NMS changed their fiscal behavior after adopting EU fiscal target, this study uses the methodology proposed by Gali and Perotti (2003) and extended by Candelon et al. (2010). The idea is to estimate the influence of the economy output gap on discretionary policy, which is approximated by the structural (primary) budget balance. In other words, fiscal policy is assessed from the perspective of a reference value that is not influenced by the cyclical component. In this study, the reference value is the potential GDP.

The workhorse panel model specification may be written as:

$$
\begin{aligned}
d_{i, t} & =\beta_{0}+\beta_{d}^{B E U} d_{i, t-1}+\beta_{d}^{A E U} d_{i, t-1} \\
& +\beta_{g a p}^{B E U} E_{i, t-1}\left[g_{i, t}^{B E U}\right]+\beta_{g a p}^{A E U} E_{i, t-1}\left[\operatorname{gap}_{i, t}^{A E U}\right] \\
& +\beta_{b}^{B E U} b_{i, t-1}+\beta_{b}^{A E U} b_{i, t-1}+B^{B E U} \Omega_{i, t}^{B E U}+B^{A E U} \Omega_{i, t}^{A E U}+u_{i, t},
\end{aligned}
$$

where $d_{i, t}$ is a proxy for structural budget balance, $E_{i, t-1}\left[g_{a p} p_{i, t}\right]$ reflects the output gap expected at a previous period and $b_{i, t}$ is the debt level. Matrix $\Omega$ consists of control variables, described in detail later, and $B$ is a corresponding vector of coefficients. Subscripts $i$ and $t$ refer to country and time dimensions respectively. The error term consists of individual and time-specific effects $\left(u_{i, t}=v_{i}+\varepsilon_{i, t}\right)$. The model distinguishes between the influence of output gaps on the discretionary policy before $\left(\beta_{\text {gap }}^{B E U}\right)$ and after $\left(\beta_{\text {gap }}^{A E U}\right)$ the structural break in 2004. Also, the control variables are split before and after EU entry as well. In fact, since we are endowed with quarterly data, we cut the sample in the last quarter of 2004. To correct for the country size, all of the variables are taken relative to GDP.

Taking the expectation of the output gap at a previous period makes a clear sense. Any government decides on fiscal policy using the expected output gap variations (Gali and Perotti, 2003). This study assumes rational expectations $\left(E_{t-1}\left[g_{a p}\right]=g a p_{t}\right)$ which is not far from reality taking into account that the fiscal authorities should know the response functions. This assumption is in line with the literature (Gali and Perotti, 2003; Candelon et al., 2010; Wyplosz, 2006; Marinheiro, 2005).

Positive values of $\beta_{g a p}^{B E U}$ or $\beta_{g a p}^{A E U}$ indicate counter-cyclical discretionary policy in a given period. In fact, this suggests that a fiscal authority was increasing structural budget balance during upswings which is exactly the definition of a counter-cyclical fiscal behavior. The $\beta_{d}$ coefficient suggests that a fiscal authority is concerned about previous period conditions and tries to include them in the current fiscal policy. This makes a clear sense. If a government is worried about the deficit levels from the past, it should increase today's balance to stabilize it. Additionally, more technically speaking $\beta_{d}>0$ indicates extrapolative or a kind of trend-following while $\beta_{d}<0$ reveals mean reversive behavior. The stationarity of the deficit time series is supported by $\left|\beta_{d}\right|<1$ (Roodman, 2006).

The specification of the model may lead to an endogeneity bias which arises between structural deficit and output gap. To correct for that, the instrumen- 
tal variable (IV) technique is used with a standard fixed effects model. ${ }^{3}$ To determine the proper instruments we follow closely the settings from Gali and Perotti (2003) and Candelon et al. (2010) and use up to the second lag of the output gap in the United States. Clearly, one would expect a high correlation between the lagged US and current EU production as a result of high trade flows and foreign direct investments. It is, however, doubtful to find a relationship between it and the structural budget deficits across the EU, which should make it a good instrument. Additionally, its validity is assessed statistically.

\subsection{Data}

For a first step, an illustration of the relevant variables is a good mean to get an idea of the economic circumstances and public finances in the NMS and the OMS. The data for the following eight figures comes from the European Central Bank (2013) and the International Monetary Fund (2013).

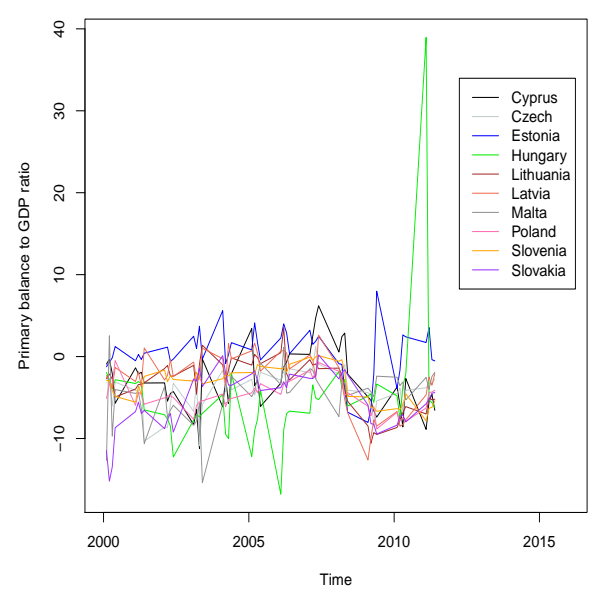

Figure 1: Primary balance ratio NMS.

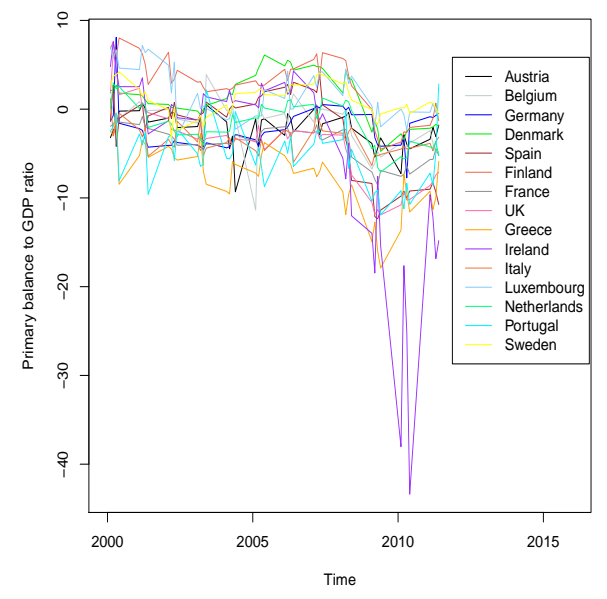

Figure 2: Primary balance ratio OMS.

The variables we take into consideration in our analysis refer to the central public finance indicators as well as to instruments which governments may influence. As a proxy for measuring discretionary fiscal policy, the dependent variable in our setting, we chose the primary balance to GDP ratio (Gali and Perotti, 2003). This is a parameter which the administration can directly influence through its budget, tax or spending (in general fiscal) policy. The data for

\footnotetext{
${ }^{3}$ (Candelon et al., 2010) applies the dynamic panel method to correct for the endogeneity bias. Originally, the dynamic panel technique was designed for large- $\mathrm{N}$ and small- $\mathrm{T}$ samples, meaning for settings with many individuals and limited number of periods. In our dataset, however, we observe the opposite. Therefore, we favor the panel IV technique over the dynamic panel methods.
} 


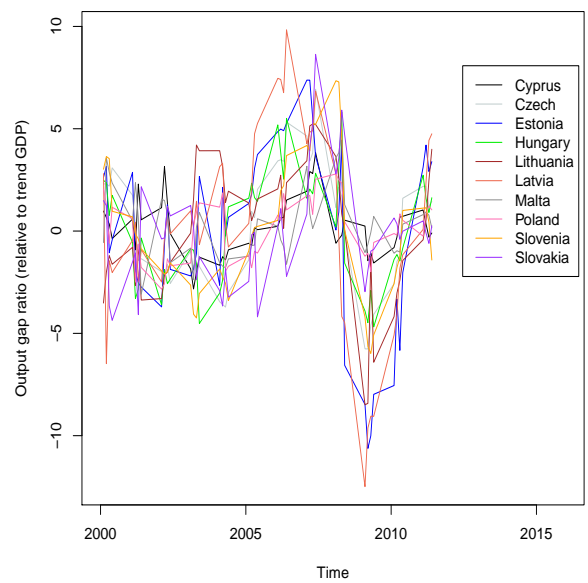

Figure 3: Output gap ratio NMS.

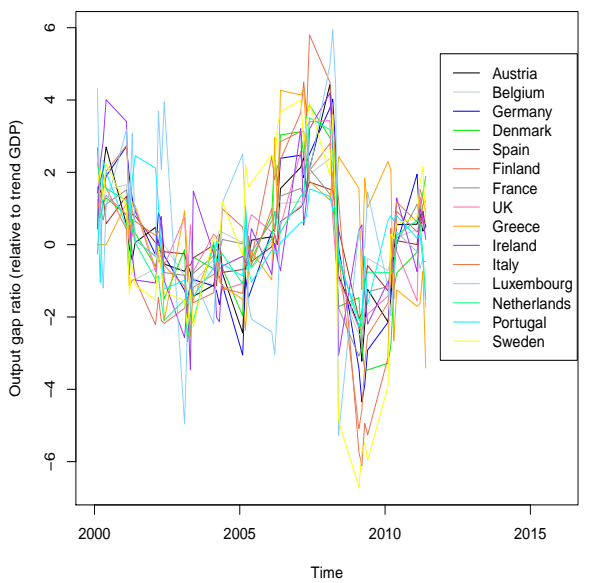

Figure 4: Output gap ratio OMS.

the primary balance ratios is depicted in figures 1 for the NMS and 2 for the OMS.

What concerns the primary balance ratios for the NMS, figure 1, certainly the one-off effect in Hungary in the first quarter 2011 is a distinctive feature. This irregular budgetary surplus was due to revenues from a shift of pension assets (International Monetary Fund, 2012). ${ }^{4}$ Besides that, the primary balance ratios mainly oscillate around zero. For the OMS, figure 2, generally a slight negative tendency of the primary surplus ratios may be observed with the extreme values of Ireland in 2010, due to stabilization of the banking sector. Soon afterwards, in November 2010, Ireland applied for financial assistance with a volume of 85 billion Euros (EFSF (European Financial Stability Facility), 2013). Also for Greece a severe deterioration of the primary balance ratio is depicted for the crisis years, however, for both economies some improvement is visible for the recent observations.

Regarding the explanatory variables, our central regressor is the output gap ratio. It is constructed by calculating the difference between the observed GDP value, denote it by $Y$, and the GDP trend, $Y^{*}$, relative to the GDP trend: $\left(Y-Y^{*}\right) / Y^{*}$. Obviously, positive values indicate economic booms while negative values represent downswings. The data is depicted in figures 3 for the NMS and 4 for the OMS. The output gap ratios of the NMS, figure 3, generally show a slight positive trend until about 2007, which, however then collapsed with the financial and debt crisis. Extreme negative values can be observed in Latvia and Estonia in 2009. Latvia also shows the highest output gap ratio in the last quarter of 2006. Recently, some catching up tendency for most economies

\footnotetext{
${ }^{4}$ This outlier does not bring any qualitative change to the estimation results so as to the final inference. Therefore, we decide to leave it in the dataset in order to make it more methodology consistent.
} 
can be observed. For the OMS, figure 4, the general pattern is more volatile: the output gap ratios mainly decrease towards the early 2000s, afterwards they improve until about 2007 with especially large positive values for Finland and Luxembourg. Certainly, the situation deteriorated with the outbreak of the crisis. Nevertheless, the recent observations indicate a slow recovery and upward trend in the output gap for many of the OMS.

Due to the recent developments with the financial and debt crisis afflicting Europe, the plots of the debt to GDP ratios and the interest rate gap (compared to Germany's long run bond yield) have been chosen to visualize the situation for the time span 2000-2011. Certainly, the public debt to GDP ratio is included as an explanatory variable, since it is one of the reference indicators from the MT which recently has become important as a result of the financial and debt crisis. (For endogenity and likely correlation effects it is included in lagged terms.)



Figure 5: Debt ratio NMS.

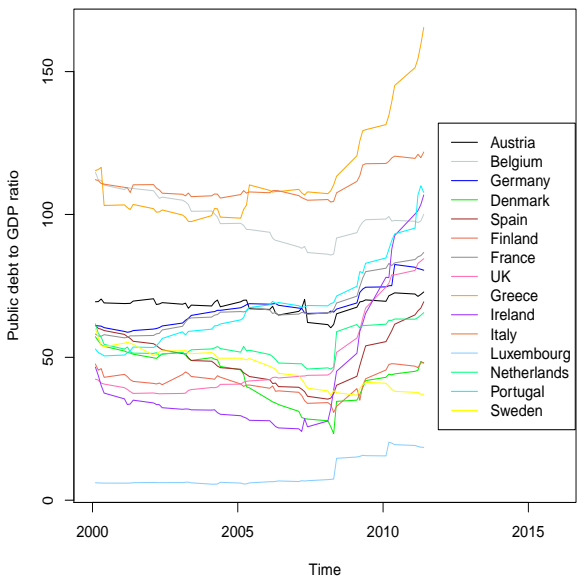

Figure 6: Debt ratio OMS.

Without any doubt, the evolution of the debt to GDP ratios in figures 5 and 6 has significantly been shaped by the crisis. The debt ratio level of some of the OMS used to be higher than for the NMS, for instance in Belgium, Greece and Italy the initial values in 2000 were above $100 \%$. Moreover, within the group of the NMS some countries also show a decline of their debt ratios after the 2004 enlargement (our reference year for the behavior change due to the EU extension), such as Cyprus, Malta and Slovakia. Thus, while for the OMS the distinctive feature here is an increase in public debt during the crisis, many of the NMS's debt ratios additionally tend to be shaped by the 2004 enlargement.

Further, in order to take into account possible crisis volatility the interest rate spreads from figures 7 and 8 are included in our model. They are deter- 
mined by the difference between the individual long run government bond yield compared to the reference value of the German log run bond yield. The de-

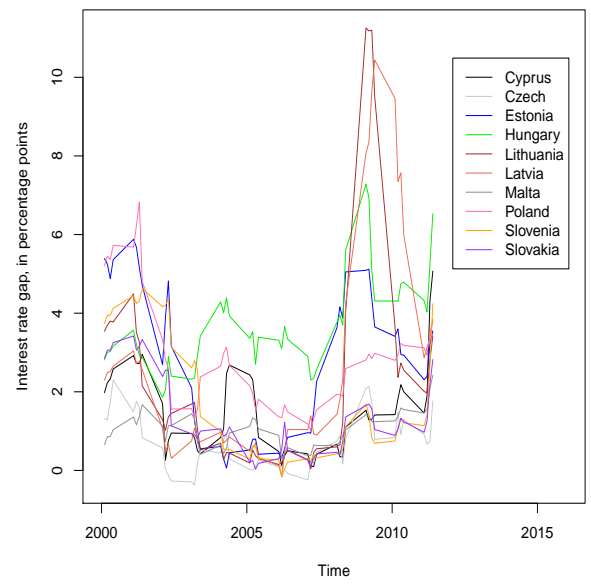

Figure 7: Interest rate gap NMS.

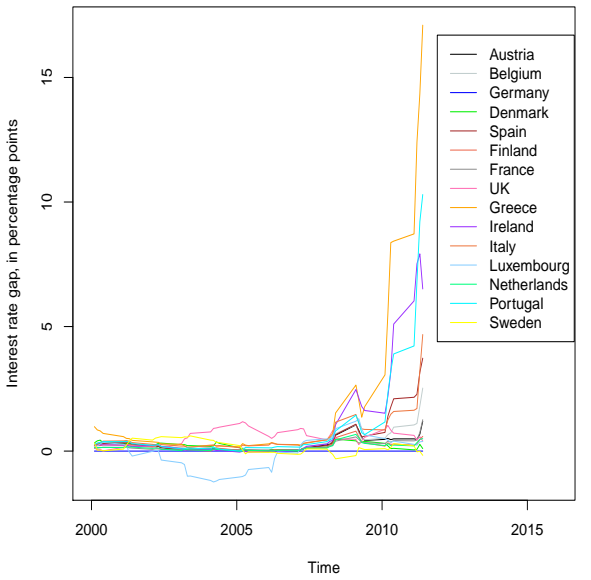

Figure 8: Interest rate gap OMS.

velopment of the spreads reveals a familiar pattern: figure. 7 shows an almost $\mathrm{u}$-shaped run for the NMS, which also displays the dynamics of the proceeding of the European integration. Many of these interest rate gaps were decreasing until about 2004 and then stayed low until about 2008. With the outbreak of the crisis they began to rise again. For the OMS's spread development in figure. 8, again, the crisis years shape the characteristic run.

Moreover, to capture potential influence of political effects, a dummy variable for parliamentary elections is added to the model for the years when the election took place. Such a specification corrects for possible bias resulting from irresponsible budgetary spending in the election years (De Haan et al., 2003).

Usually, empirical analyses are limited by data quality and availability, which holds especially true for studies concerning NMS. Therefore, we used a combined data set, mainly consisting of data from European Central Bank (2013) and International Monetary Fund (2013). The election variable concerns parliamentary election dates and has been taken from International Foundation for Electoral Systems (IFES) (2013). Regarding the frequency, we employed quarterly data in order to enhance the time span, here covering the years from 2000 (Q1) until 2011 (Q4). This yields 48 observations per country and a total size of $N=480$ for NMS and $N=720$ for OMS. Obtaining a continuous and consistent series required a thorough data set preparation. Seldom missing observations had been extrapolated in order to make the panel balanced. Moreover, for calculation of the GDP trend $Y^{*}$, the real GDP series had been filtered with a Hodrick-Prescott method in $R$ 2.9.0. Finally, all variables had been seasonally adjusted. 


\section{$3.2 \quad$ Results}

The regression outcomes for the NMS are presented in Table $1 .{ }^{5}$ For clarity reasons, we present the results for all the model specifications. First, for the full sample and standard regressors (lagged budget balance, output gap ratio and lagged debt ratio - all before and after EU entry) see Model 1, presented in the first column. Taking into account the current crisis, we followed a twofold approach. On the one hand we cut the sample and consider only the time period before the crisis (Q12001-Q42008), model type 2, second column. On the other hand, we include the interest rate gap, model type 3, third column. Finally, as an additional specification we also include an election dummy variable, capturing the influence of politics, type 4 and 5 , forth and fifths column respectively. The reason for cutting the sample in the last quarter of 2008 is twofold: on the one hand this allows to equalize the number of the degrees of freedom and on the other hand it enables to observe the behavior before the crisis began.

The results show that the coefficients of interest $\beta^{B E U}$ and $\beta^{A E U}$, which correspond to the effect of the output gap ratio before and after EU enlargement in 2004 on the primary balance ratio, are statistically significant after EU entry only. Interestingly, all $\beta^{A E U}$ coefficients are positive indicating counter-cyclical fiscal policy in NMS after joining the EU. This holds true for all model type specifications. The results suggest also that the discretionary fiscal policies before the 2004 entry were acyclical, in a sense that there was no statistically significant influence from the output gap on the structural balance. This is somehow confirming the results from Schneider and Zapal (2005) but on the aggregate level, with some countries running pro-cyclical and the other having counter-cyclical budgetary positions. These results might be interpreted in two ways proving that either the heterogeneity in fiscal behavior decreased and the fiscal change was relatively small, or the heterogeneity persisted with the 2004 effect being relatively larger. This is out of the scope of this paper to investigate this in details and we leave this interesting topic for further consideration.

Concerning the other coefficients, only the lagged primary balance turns out to be statistically significant for all of the model specifications. As expected the coefficient is positive and lies on the unit circle, confirming the stationarity (Roodman, 2006). In line with the comments from above concerning the $\beta_{d}$ being smaller or larger than zero, the results suggest a trend-following behavior. This reflects objections of the administration about previous periods conditions. Further, the interest rate gap and election variable prove to affect the primary balance significantly and negatively after 2004 entry. For the interest rate this may display the influence of the current crisis. The higher the gap, i.e. the worse the economic condition of the economy, the higher the deficit in this period. The negative election effect indicates lower surpluses in times of elections (potentially 'election gifts'), also in line with theory (De Haan et al., 2003).

Interpreting our results for the NMS from an economic policy perspective yields very interesting insights on the actual discretionary fiscal policies in a given time span. The outcomes reveal a statistically significant change towards

${ }^{5}$ All the estimations have been implemented in STATA 12. 
the counter-cyclical fiscal behavior after 2004. The result is robust with respect to almost all model specifications except for model 3, i.e. when correcting for interest rate gap only. This might suggest that countries which were suffering from the high interest rates (comparing to Germany) did not change their fiscal behavior that much. In fact, one should expect that the EU fiscal rules would be accepted mostly in countries which do not suffer from the economic turbulence (Wyplosz, 2006). However, correcting for the crisis and political forces, the change in 2004 becomes significant again, confirming previous reasoning.

Year 2004 brought a significant change to almost all of the regressors. One may claim that this is a result of an increased number of degrees of freedom for the after-2004-specification. However, even if we correct for the sample size, the results remain similar. In fact, it seems that the EU entry did not only change the discretionary fiscal behavior among the NMS but it also shaped the fiscal responses against different financial and political forces.

One should pay attention to the possible over-identification problems, resulting from the choice of instruments. The number of lags in the instrument space was chosen in order to yield a maximum Sargan test p-value. Nevertheless, they might seem troubling for some of the readers. When considering the p-values for the standard Sargan test for over-identifying restrictions, one should keep in mind the possible heteroscedasticity of the errors which could influence the test performance (Roodman, 2006). In fact, the magnitude of the p-values is similar to the one presented in Candelon et al. (2010) for the comparable model specifications, being acceptable at the $5 \%$ significance level. Therefore, in order to draw conclusions, one should pay attention to the holistic perspective of our estimation results. The well specified model, i.e. model with the truncated time span, confirms the main inference from the other models together with satisfying the over-identification restrictions.

Interestingly, one may think of the reason why there are over-identification problems with years after 2008. An explanation could lie in the increased heterogeneity in reactions to the financial crisis among the NMS. Clearly, different NMS got different exposure to foreign risks and were differently affected by the crisis. For instance countries like Lithuania, Estonia or Latvia suffered from a huge economic losses immediately after the US crisis. At the same time, the economic situation in Cyprus or Slovenia was mostly affected in the aftermath of the sovereign debt crisis which spread across Europe two years later. Countries like Poland were pretty robust to the foreign shocks as a result of a strong internal consumption and a relatively low degree of internalization of the capital flows. Hungary, however, is a kind of a special case, as the situation may be reckoned to be strongly politically influenced. Concerning Slovakia and Czech Republic, the situation indicates to be relatively similar to Poland, while the behavior of Malta resembles Cyprus. 


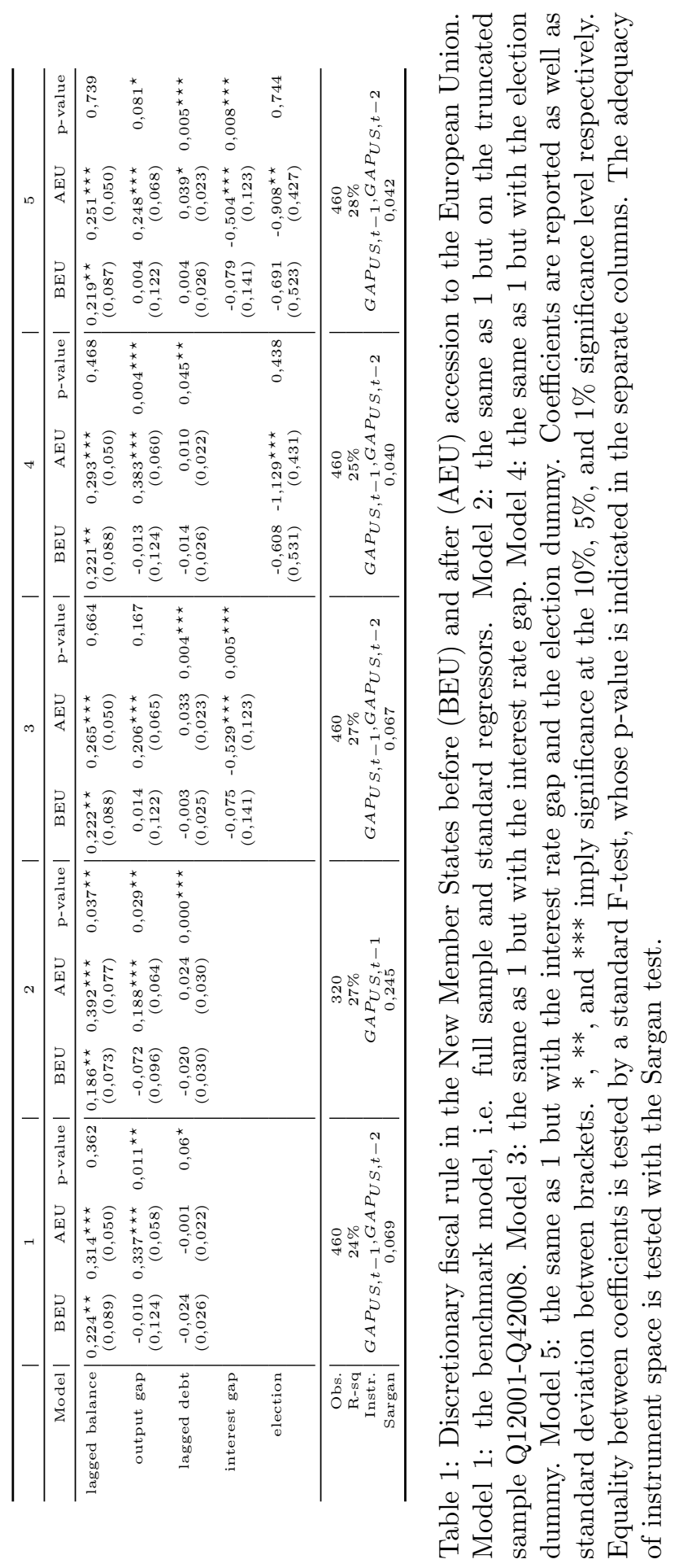




\subsection{Comparison to the OMS}

The results for the OMS are presented in Table 2. The model specifications remain the same as in the previous section.

Since the results suffer from the over-identification bias, they should be taken with caution and should be treated as a comparison for the NMS rather than suiting to draw actual policy conclusions from. The only well specified model, i.e. the model for the truncated time span, suggests, however, that there was no statistically significant change in fiscal behavior for the OMS in year 2004. The other model specifications confirm this. The outcomes may also suggest countercyclical policy after 2004 but it seems to be very influenced by crisis effects. On the one hand, without the crisis years (the truncated sample) the coefficient of interest looses statistical significance and on the other hand including the crisis years yields significant positive effects of the output gap and negative effects of the debt ratio (unsuitable behavior).

The goal of this comparison is to check if there were any other factors in 2004 which could have led to a switch in the discretionary fiscal policies among the member states. It seems that the 2004 effect could be clearly recognized for the NMS only, with no clear-cut evidence for a change in the other member states. Interestingly, one may get an impression that the fiscal policies in the OMS are shaped by different factors than these in the NMS. The over-identification problems and the counter-intuitive sign for the lagged debt variable are just symptoms of that phenomenon. One may also observe no political influence on the fiscal behavior, together with much higher R-squared coefficients.

In fact this might be the confirmation of previously mentioned literature, which pointed out the problem of lack of incentives to run more counter-cyclical fiscal policies and curb down the deficit and debt levels once in the EU (Wyplosz, 2006; Wyplosz, 2002). Our analysis confirms that the NMS were trying to satisfy the MT and SGP regulations and they actually changed their fiscal behavior entering the EU. It is difficult, however, to determine the fiscal stance of the OMS. Certainly, they did not change their fiscal policies in 2004. Moreover, their fiscal behavior was mostly driven by the crisis effects with barely any insight on other indicators. All this might be viewed as a contribution towards the ongoing discussion on the relevance and effectiveness of the EU fiscal standards. 


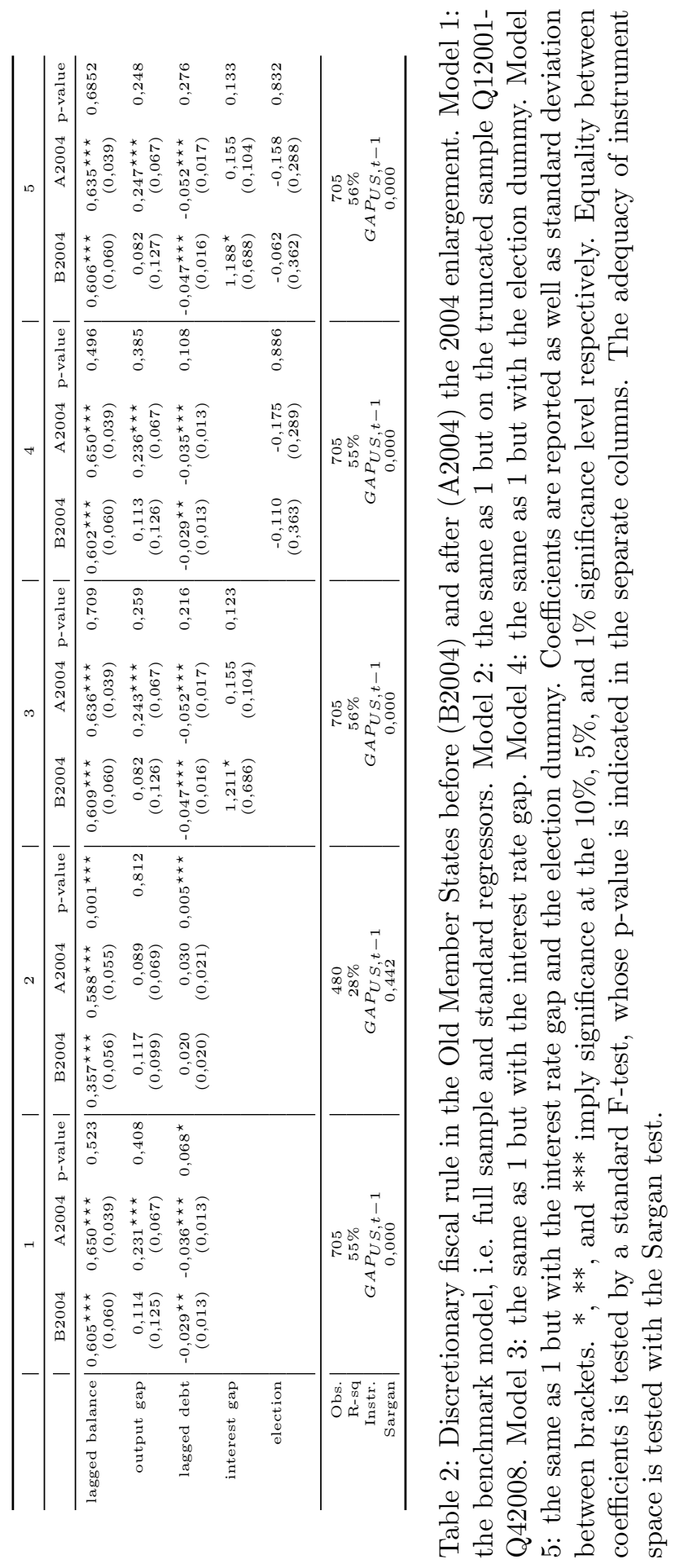




\section{Summary}

In line with the economic literature and recent considerations on the European integration and adoption of the fiscal rules, this paper continues and contributes to the discussion by addressing the aspect how fiscal rules affect discretionary policy behavior of governments in the European Union. In times like these, with the financial and debt crisis affecting especially Europe, such an analysis certainly is of special relevance.

Our study includes $25 \mathrm{EU}$ member economies, however, a special focus is set on ten NMS, which joined the EU in 2004. Based on quarterly data covering the years 2000 until 2011 and different specifications regarding the explanatory variables, a panel regression with the IV technique has been implemented. In order to study the influence of the adoption of fiscal rules on discretionary policy the model estimates the relationship between the structural primary balance ratio and the central regressor: the output gap ratio, which represents the economic performance and situation.

The results indicate a statistically significant switch towards counter-cyclical fiscal policy behavior of the NMS after their EU entry. The specification methods confirm previous findings of possible heterogeneity in fiscal behavior in our sample (Schneider and Zapal, 2005). On average, however, NMS were running stabilizing budgetary positions as of the year 2004 .

For reasons of comparison the same investigation has been implemented for the OMS. The results suggest that the fiscal behavior among the OMS was driven by different factors from the ones among the NMS. It seems that once in the EU, a member loses the incentives for prudent fiscal behavior. This phenomenon has been recognized in previous studies and is currently a topic of consideration of the European Commission, European Parliament and national governments in the EU (Schaechter et al., 2012). We believe that this study will contribute to the ongoing discussion, yielding a mechanism towards more prudent fiscal performance once in the EU.

Certainly, these results should not be interpreted in isolation. The budgetary policies have been considered as an everlasting topic for discussion in the European history and might be affected by other factors than we included in our analysis. In order to get a comprehensive picture, one should consider country-specific research, treating the fiscal performance of each NMS individually. Our outcomes reveal just a top of an ice berg in the fiscal performance in the NMS after the EU entry.

\section{References}

Alesina, A., Tabellini, G. and Compante, F. R. (2008). Why is fiscal policy often pro-cyclical? Journal of the European Economic Association, 6, number 5, $1006-1036$.

Annett, A. (2006). Enforcement and the Stability and Growth Pact: how fiscal 
policy did and did not change under Europe's fiscal framework. IMF Working Paper, 6, number 116.

Artis, M. and Buti, M. (2000). Close to balance or in surplus: A policy maker's guide to the implementation of the Stability and Growth Pact. CEPR Discussion Paper, 2515, 1-38.

Beetsma, R. (2001). in A. Brunila, M. Buti and D. Franco (eds.) The Stability and Growth Pact, chapter Does EMU need a stability pact?, pp. 23-52. Palgrave.

Buti, M., Eijffinger, S. and Franco, D. (2003). Revisiting EMU's Stability Pact: a pragmatic way forward. Oxford Review of Economic Policy, 19, number 1, $100-111$.

Buti, M., Franco, D. and Ongena, H. (1997). Budgetary policies during recessions - retrospective application of the Stability and Growth Pact to the post-war period. European Economy - Economic Papers 121. Directorate General Economic and Monetary Affairs, European Commission.

Candelon, B., Muysken, J. and Vermeulen, R. (2010). Fiscal policy and monetary integration in Europe: an update. Oxford Economic Papers, 62, 323-49.

De Haan, J., Berger, H. and Jansen, D. (2003). The end of the Stability and Growth Pact? CESifo Working Paper, 1093.

EFSF (European Financial Stability Facility) (2013). Publications: Frequently Asked Questions, 21 January 2013, http://www.efsf .europa.eu/ attachments/faq_en.pdf, last access June 7th, 2013.

European Central Bank (2013). Statistical Data Warehouse, available online: http://sdw.ecb.europa.eu/, last access February 15th 2013.

European Comission (2001). Public Financies in EMU 2001, volume 3. European Comission.

European Commission (2013). Economic and Financial Affairs, Financial Assistance in EU Member States, http://ec.europa.eu/economy_finance/ assistance_eu_ms/index_en.htm, last access April, 24th, 2013.

Gali, J. and Perotti, R. (2003). Fiscal policy and monetary integration in Europe. Economic Policy, 18, 534-72.

International Foundation for Electoral Systems (IFES) (2013). Election Guide, Parliamentary elections, http://www.electionguide.org/, last access May, 7th, 2013.

International Monetary Fund (2012). IMF Country Report HUNGARY 2011 Article IV Consultation and Second Post-Program Monitoring Discussions. IMF Country Report No. 12/13, Washington D.C. 
International Monetary Fund (2013). International Statistical Yearbook, IMF's International Financial Statistics. via StatistikNetz.de, DSI Data Service 8 Information.

Kydland, F. E. and Prescott, E. C. (1977). Rules rather than discretion: The inconsistency of optimal plans. The Journal of Political Economy, 85, number 3, 473-92.

Marinheiro, C. J. F. (2005). Has the Stability and Growth Pact stabilized? evidence from a panel of 12 European countries and some implications for the reform of the Pact. CESifo Working Paper, 1411.

Pendleton, H. E. (1938). The politics of fiscal policy. The Yale Law Journal, 47, number 5, 724-45.

Roodman, D. (2006). How to do xtabond2: An introduction to difference and system GMM in Stata. Technical Report. Center for Global Development.

Schaechter, A., Kinda, T., Budina, N. and Weber, A. (2012). Fiscal rules in response to the crisistoward the next-generation rules. a new dataset. IMF Working Paper W, P/12/187.

Schneider, O. and Zapal, J. (2005). Fiscal policy in new EU Member States. go East, prudent man! CESifo Working Paper, 1486, 1-28.

Von Hagen, J. (2005). Fiscal rules and fiscal performance in the EU and Japan. IMES Discussion Paper, E-5, 1-29.

Wyplosz, C. (2002). Fiscal discipline in EMU: Rules or institutions? Technical Report. European Comission.

Wyplosz, C. (2006). European Monetary Union: the dark sides of a major success. Economic Policy, 21, 207-61.

Zapal, J. (2007). Cyclical bias in government spending: Evidence from New EU Member Countries. IES Working Paper, 15, 1-23. 